\title{
An Analysis of Error Pronounciation in Arabic Vocabulary by Blind تحليل الأخطاء في نطق المفردات العربية للتلاميذ المكفوفين / Students
}

\author{
Erawati \\ SDI Nurul Huda Kartasura \\ erawati538@gmail.com
}

\begin{abstract}
This study aims to describe the pronunciation errors of vocabulary and the factors causing the pronunciation errors of vocabulary that are read by blind students at MAN 2 Klaten. The method used for this research is descriptive qualitative research. The data collection methods used by researchers to access the data required in the writing of this study are the observation method, the interview method, and the documentation method. From this research, it is known that some of the mistakes made by students include errors in ibdal, hadzf, and idhafah. The factors causing the mispronunciation of vocabulary that are read by blind students are 1) The difference between the two languages in the al-letter makhariju; 2) Students cannot see the teacher who gives examples of vocabulary pronunciation; 3) $A$ hearing mechanism that differentiates sound pronunciation; 4) Blind students do not know the meaning of vocabulary.
\end{abstract}

Keywords : Error Analysis, Mufradat, Blind.

\section{ABSTRAK}

Penelitian ini bertujuan untuk mendeskripsikan kesalahan pengucapan kosakata dan faktor penyebab kesalahan pengucapan kosakata yang dibaca siswa tunanetra di MAN 2 Klaten. Metode yang digunakan untuk penelitian ini adalah penelitian kualitatif deskriptif. Adapun metode pengumpulan data yang digunakan peneliti untuk mengakses data yang membutuhkan dalam penulisan penelitian ini adalah metode observasi, metode wawancara, dan metode dokumentasi. Dari penelitian ini diketahui beberapa kesalahan yang dilakukan oleh siswa meliputi kesalahan dalam ibdal, hadzf, dan idhafah. Faktor penyebab kesalahan pengucapan kosakata yang dibaca oleh siswa tunanetra adalah 1) Perbedaan kedua bahasa pada makhariju al-huruf ; 2) Siswa tidak dapat melihat guru yang memberikan contoh pelafalan kosakata; 3) Mekanisme pendengaran yang membedakan antara pelafalan bunyi; 4) Siswa tunanetra tidak mengetahui arti kosakata.

Kata Kunci : Analisis Kesalahan, Mufradat, Tunanetra. 
المقدمة

رأى أجيف هرماون (Nuha 2016) أن مهارة الكلام هي القدرة على التعبير عن أصوات او

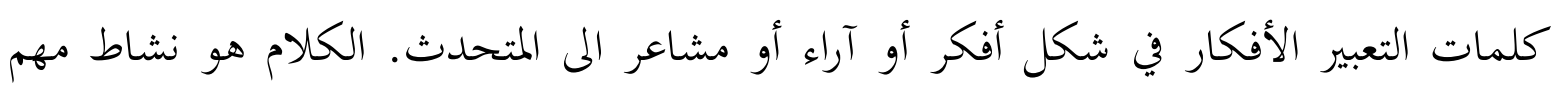
للغاية في الحياة، في حاجة إلى التواصل بشكل عام يستخدم الإنسان كلمات أكثر من الكتابة. مهارة الكلام هي القدرة على التواصل في كلا الاتحاهين بين المتحدث و المستمع. إن كل إنسان يولد في العالم ليس كاملاً. في بعض الأحيان يولد اليشر بأجة القصور التي يعانون منها، ويطلق عليهم، ويطلق عليهم اسم الأطفال ذوي الاحتياجات الخاصة. أحد الأطفال الذين يطلق عليهم

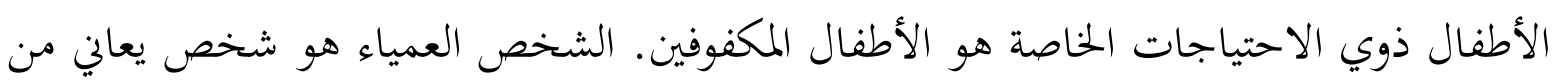

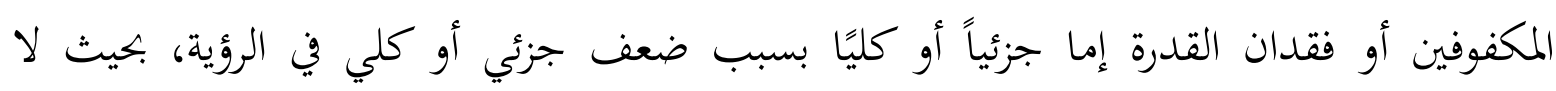
يستطيع الطفل استخدام رؤيته في الحياة اليومية. إن كل إنسان يولد في العالم ليس كاملاً. في بعض الأحيان يولد اليشر بأجة القصور التي التيأ يعانون منها، ويطلق عليهم، ويطلق عليهم اسم الأطفال ذوي الاحتياجات الخاصة. أحد الأطفال

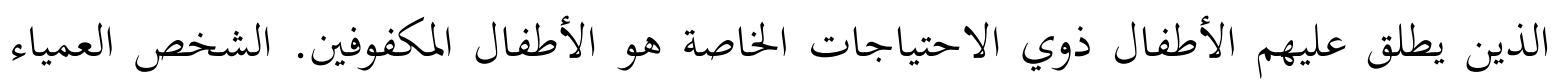

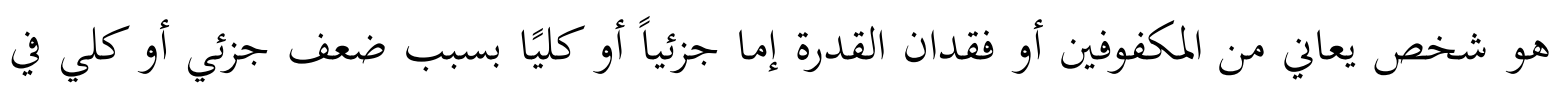
الرؤية، بحيث لا يستطيع الطفل استخدام رؤيته في الحياة اليومية.

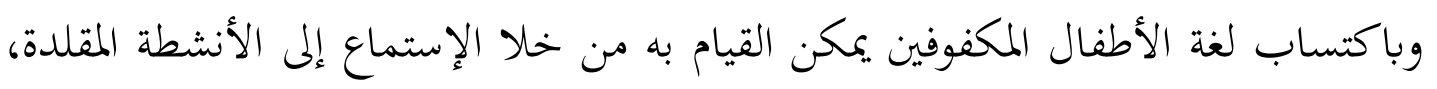
ولكن في عملية التقليد لا يمكن أن ينفصل عن الأخطأ، خاصة في تعلم اللغة العربية. في اللغة العربية هناك أصوات لغوية ليست في الإندونيسية، كالحروف ث و و ح وخ و ذ و ص و و ض و و ط و و ظ وع وغ وش .استنادا إلى المستوى اللغوي، يمكن تصنيف أخطأ اللغة إلى : أخطاء اللغة في مجالات علم الفونولوجيا و المورفولوجيا وبناء الجملة (عبارات، جمل) و دلالات الكات الكلام و الحوار .(Taringan, 2009)

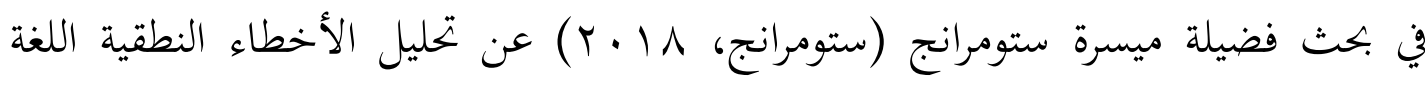
العربية في معهد العصري الكوثر بيماتنج سيانتر يشرح أن كثير من الطلاب الذين يقرؤن المفردات

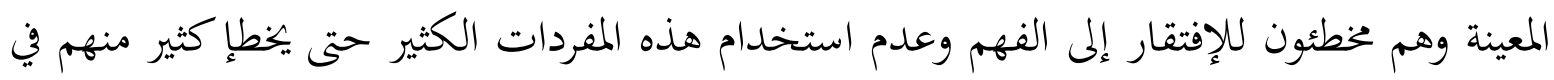

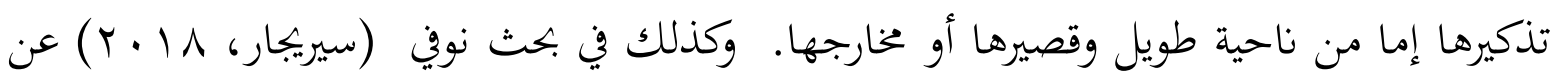


تحليل الأخطاء اللغوية لدى الطلبة نور الحكيم تمبونج الحديث (دراسة الأصوات) توجد أن الأخطاء

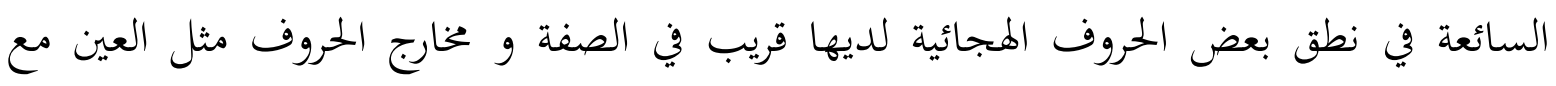
الهمزة، و الدال مع الذال. وسوى ذلك من أسباب الخطياءت هي أن بعض صوت الحروف الهجائية لا توجد في اللغة الإندونيسية.

تعليم المفردات في المدرسة العالية الإسلامية الحكومية الثانيةكلاتين يطبق المعلم الطريقة تقليد التحفيظ (memorization). الطريقة تقليد التحفيظ هي طريقة للتعلم عن طريق تقليد الطلاب

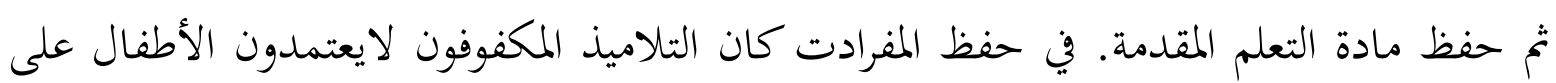
السمع و الذكرة، ثم يقلدون المفردات التي يقرأها المعلمون والأقران. حتى في نطق المفرادت هناك موجد أخطاء نطق لأن عنده حروف الهجائية غير موجد في اللغة الإندنيسية و نطق الحروف هجائية المتشابهة بالمقلوب وغير قادر التمييز بين نطق الحروف هجائية المتشابهة. بناء على مقابلة مع أحد معلمي اللغة العربية أخطاء في نطق لدى التلاميذ المكفوفين في حروف الهجائية التي تكاد

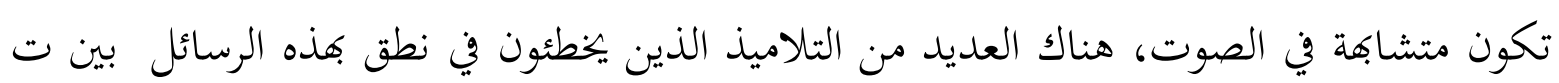
و ط، س ش و ص، ء و ع. فيبحث هذا البحث عن "تحليل الأخطإ في نطق المفردات المقروؤة للتلاميذ المكفوفين بالمدرسة العالية الإسلامية الحكومية الثانية كلاتين. و سننظر فئر هذا البحث إلى أخطإ التلاميذ المكفوفين في نطق المفردات والعوامل المسببة للأخطإ في نطق المفردات المقروءة. طريقة البحث

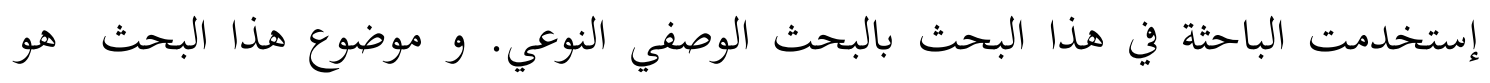

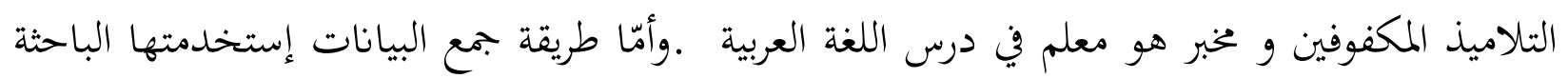
للو صول علي بيانات المحتاجة في كتابة هذا البحث فهي طريقة الملاحظة و طريقة المقابلة و طريقة التوثيقة. وأمّا الطريقة لتصحيح البيانات فهي التثليث، وأما الطريقة تحليل البيانات الوصفية ثلاثة أقسام و هي بحليب البيانات و تقديم البيانات وإتخاذ الجلاصة. 


\section{نتائج البحث \\ تحليل أخطاء النطق لتق}

وفقا لقاموش اللغة الإندونيسية (KBBI) يتم تعريف الأخطأ بواسطة ، الشيئ يخالف

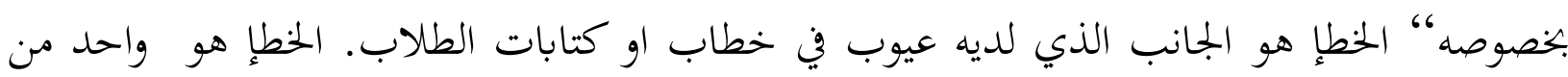
أجزاء من المحادثة او جزء من التكوين " تنحرفه، هو من من قاعدة أساسية او من قاعدة لغة البالغين. اضطرابات النطق هي أخطإ كلامية تنتج عن أخطإ في حركة الفك والشفاة واللسان أو عدم تسلسلها بشكل مناسب، بحيث يحدث استبدال أو حذف أو إضافية أو تشويه.

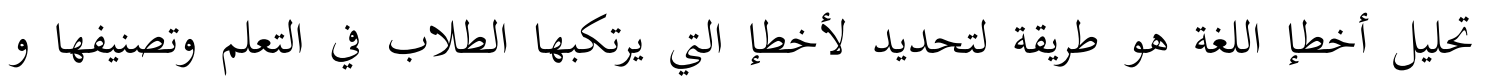

تفسيرها بشكل منتظم في تعليم لغة أجنبية أو لغة ثانية باستخدام النظرية والإجراءات اللغوية. إن تحليل الأخطا (Error Analysis) هي فرع من فروع علم اللغة التطبيقي(Applied Linguistics) أخطاء اللغة هو عمليّة تفحص الأخطإ التي تحدث في تعلّم الغة ثانية تدف إلى تقيل ومنع حدوث الأخطأ مرّة أخرى. تحليل أخطإ اللغة هوطريقة لتحديد و تصنيف و تفسير الأخطإ المنهجية التي يرتكبهاالتلاميذفي تعلم اللغة الأجنبية أو اللغة ثانية بالستخدام النظرية والأجراءت اللغوية.

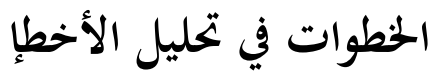

أن محللي الأخطإ يعتمدون في بحوثهم اللغوية التطبيقية على ست خطوات.وتلك الخطوات

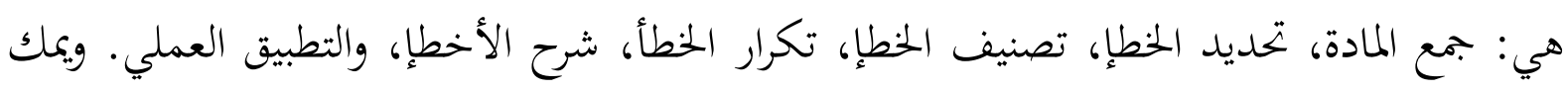
نقاشها فيما يلي:

ا ـ جمع المادة، هذه الخطوة تتعلق بمنهجية البحث، وكيفية جمع المادة اللغوية، وعدد المتعلمين، وغيرها

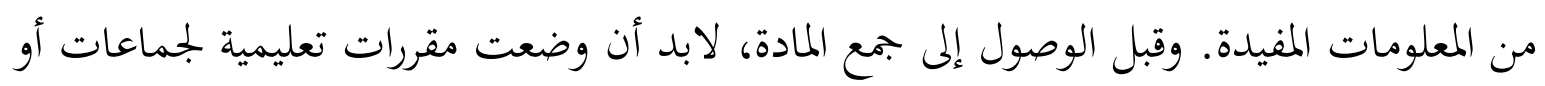
لإفراد لا لفرد. والمفروض أن تكون هذه الجماعات متجانسة في معايير العمر، والمستوى، والمعرفة

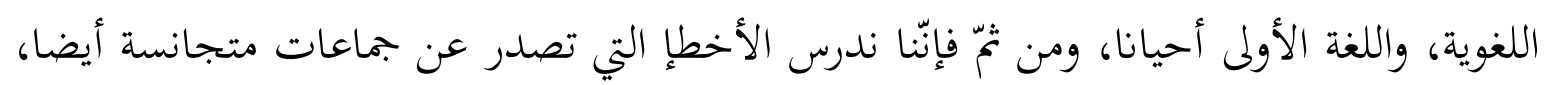
أي الأخطإ التي لما صفة الشيوع في هذه الجماعات. 
r. تحديد الخطإِ إن عملية تحديد الأخطإ ليست بالأمر السهل. ولذلك يجب على الباحث في تحليل

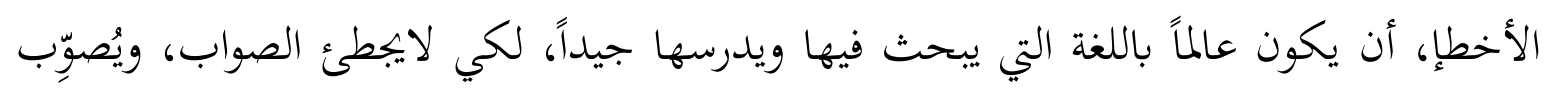

r.تصنيف الخطإ، هذه الخطوة، تشمل التعرف على أخطإ الدارسين وتصنيفها حسب نوعها. ويجري وصف الأخطإ على كل مستويات الأداء، في الكتابة، والأصوات، والصرف، والنحة النحو، والدلالة.

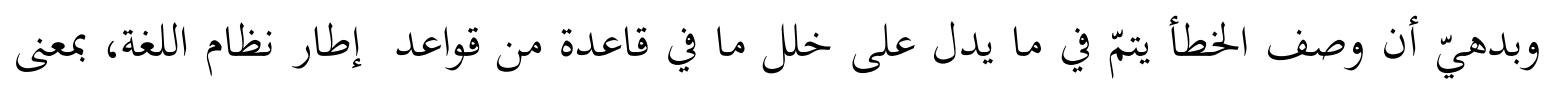

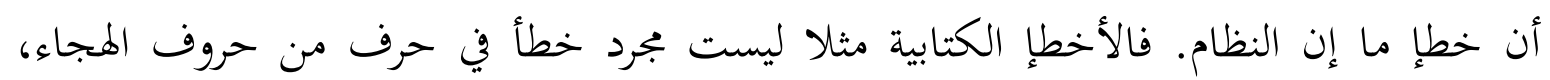
لكنها قد تكون دليلا قويا على فقدان قاعدة في نظام اللغة. ويمكننا أن نصنف تصنيف الأخطإ تحت فئات مختلفة مثل: الأخطإ النحوية، والصرفية، والصوتية، والبلاغية، ولفئ والأسلوبية (تحليل

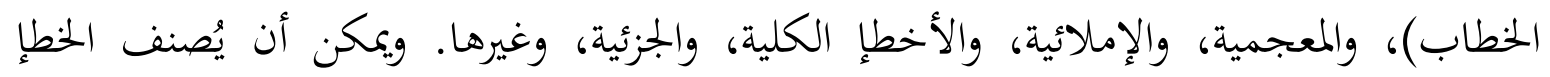

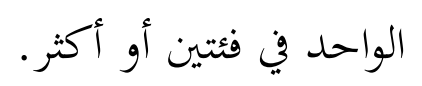

ع. إحصاء الخطإ، بعد أن يكون الخطأ محدودا على تصنيف ما، يرتب الباحث تلك الأخطإ حسب إنب عدد حدوثه في كل تصنيف، وقام بإحصاءها.

ه. شرح الأخطإ، إن وصف الأخطإ عملية لغوية صرفة، بينما شرحها عملية لغوية نفسية بامتياز.

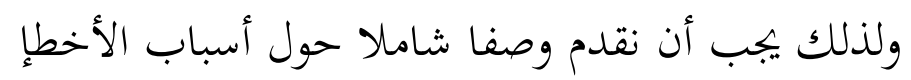

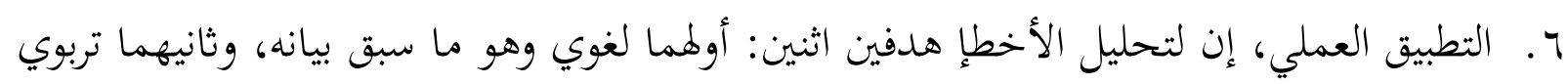
وتطبيقي وهو ما سنعالجه فيما يلي، وهو التطبيق العملي على الأخطإ التي يرتكبها المتعلمون.

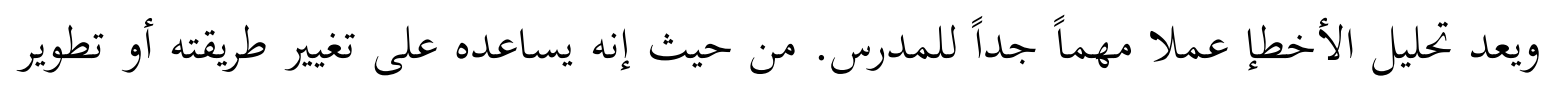

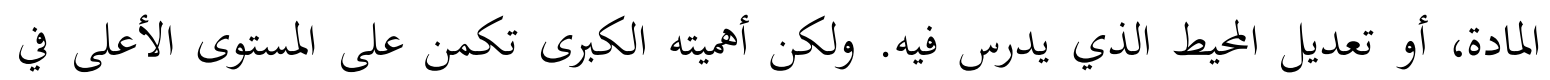
التخطيط في المقررات الدراسية، والمقررات العلاجية، وإعادة التعليم، وتدريب المعلمين أثناء العمل

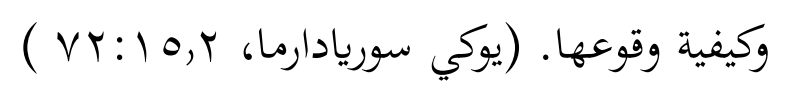
أسباب اخطإ النطق

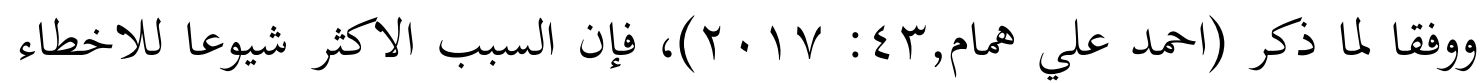
يرجع إلى الإختلافات في نظام اللغة الأم مع اللغة الثانية أو اللغة المستهدفة, وذلك لأنه 
يميل إلى نقل أنظمة لغته الأم وتطبيقها على أنظمة اللغة الهدف, وبناء على ذلك فإن من

$$
\begin{aligned}
& \text { يتعلم لغة أجنبية يواجه صعوبات صوتية تعود لأسباب منها : } \\
& \text { 1 ـ إختلاف اللغتين في مخارج الأصوات } \\
& \text { r. إختلاف اللغتين في التجمعات الصوتية } \\
& \text { r. إختلاف اللغتين في مواضع النبر و التنغيم } \\
& \text { ـ ـ إختالاف اللغتين في العادات النطقية }
\end{aligned}
$$

وفيما يلي الأسباب المحددة لأخطإ النطق لدى التلاميذ المكفوفين

ا ـ الميكانزم السمعى الذي يقوم بالتمييز بين النطق الأصوات, وبالتالي إذا حدث خطإِ في

سمع فقد يؤدي ذلك الى حدوث خطأ في نطق لدى الأطفل المكفوفين لأن الأطفل لا

$$
\text { يمكنه رؤية كتابة و فم المعلم. في (أيمن عبدالرحمن العقباوي :.ب). }
$$

r. المعلم نفسه، قد يكون المعلم سبباً لوقوع المتعلمين في الأخطإ كأن يعاني المعلم من مشكلة نطق الأصوات لأنّ المتعلم دائماً يقلد صوت معلمه. في( روضة محمد كوري

$$
\begin{aligned}
& \text { عبد الله و حسن منصور أحمد سوركتي, Y Y: 1 | • ( ) } \\
& \text { مفهوم المفردات وأنواعها }
\end{aligned}
$$

المفردات هي الجزء الأهمية في عنصراللغة، الذي يستخدم كلغة منطوقة ومكتوبة،

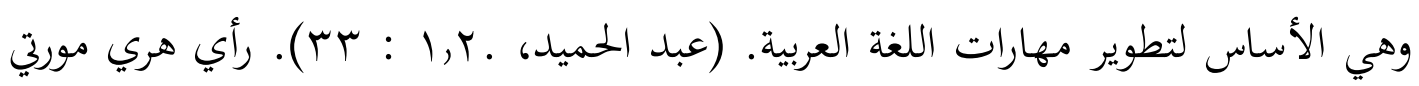

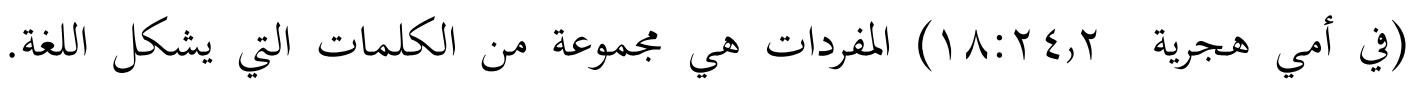

الكلمات هي أصغر جزء من اللغة المجانية.

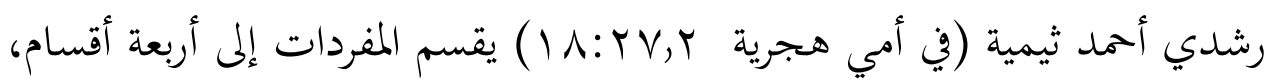

ومن هذا القسم يصنف إلى مهمة و ظائفها، كما يلي:

1. تقسيم المفردات وفقا لإتقان اللغة

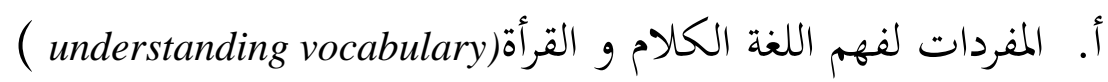

ب. بم: المفردات لكلام (speaking vocabulary) 
ATHLA : Journal of Arabic Teaching, Linguistic And Literature, 1, (2), 2020

$$
\begin{aligned}
& \text { ج. المفردات لكتابة (writing vocabulary) } \\
& \text { د.المفردات المحتملة } \\
& \text { Y. تقسيم المفردات حسب معناها } \\
& \text { أ. أكلمات الأساسية } \\
& \text { ب. بـ الكلمات الدالة } \\
& \text { ج. الكلمات بحتمعة }
\end{aligned}
$$$$
\text { ץ. تقسيم المفردات حس ب خصائص الكلمة }
$$$$
\text { أ.المفردات المهمة (service words) }
$$

ب. المفردات الأساسية خاصة(special content words)

$$
\text { ع. أ. تقسيم المفردات حسب استخدامه }
$$

و من حيث الوظيفة، تقس المفرادت الى قسمين هما المفرادت المعجمية هي المفردات

لديها معنى في القاموس، مثل بيت و قمر و قلم و غير ذلك. و المفرادت الوظيفية هي المفرادت الوظيفية هي لديها مفرادت وظائف معينة، مثل حرف الجرى و إسم الإشارة و إسم الموصول، و ضمر وغيرذلك.

التعليم للتلاميذ المكفوفين

مصطلالح المكفوفين يستخدم ليبين الأفراد الذي يعانون من العمى التام أو

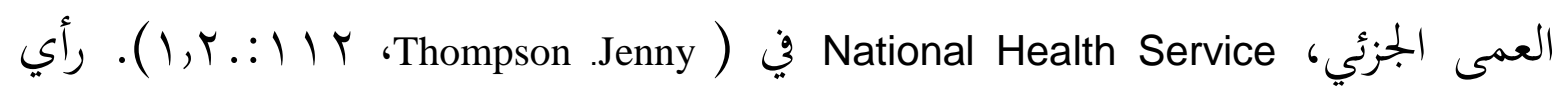

سومنطرى، في (بامبانج فوترنطا 0 : : 10 . ب) ضعف البصر لا يهدى الى أعمى فقط، ولكن يهدى الى الأفراد لديهم البعر محدودة. الأطفال المكفوفون يستطيع أن يعرف من خلال عدة شروط

$$
\begin{aligned}
& \text { ا ـ حدة البصر تفتقر أقل من الناس العاديين. } \\
& \text { r . يحدث أن ينقص في عدسة العين. }
\end{aligned}
$$


ATHLA : Journal of Arabic Teaching, Linguistic And Literature, 1, (2), 2020

$$
\text { r ـ يحلدث أن يتلف عصب الدماغ المتعلقة ببعر. }
$$

وأما رأي هيذر ميسون وأخواتما، في ( بورواكا هادي V... Y : I ) هناك السّبب ضعف البصر

$$
\begin{aligned}
& \text { كما يلي: } \\
& \text { ا ـ عوامل الوراثية }
\end{aligned}
$$

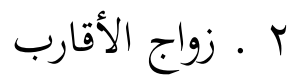

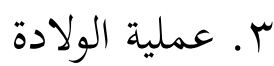

$$
\begin{aligned}
& \text { ع ـيعاني أطفال الأمراض يسّبب المكفوفين } \\
& \text { هـ عوامل الحادثة } \\
& 7 \text { ـ إعتماد على المخدرات } \\
& \text { V . عدوى من الحيوانات } \\
& \text { م. مقس الحار } \\
& \text { وعلامات المكفوفين رأى (جمل محمد . م : ... ) مشكلة ضعف البصر يستطيع أن يعلم بعلاما، } \\
& \text { كمايلي: } \\
& \text { أ. عالامات المادية } \\
& \text { - مقلة الغين تدول دائما } \\
& \text { - عيون تتحرك المركة دائما } \\
& \text { - لايستجيب للضوء الساطع } \\
& \text { - هناك بقع بيضاء على بؤبؤ } \\
& \text { - حواف عيون الحمراء } \\
& \text { - عيون المائي دائما } \\
& \text { - عيون حساسة للغاية للضوء } \\
& \text { ب. علامات السلوك } \\
& \text { - خطاء مرار في يفهم حرف } \\
& \text { - عيون اليفرك دائما } \\
& \text { - عيون العمزة دائما }
\end{aligned}
$$


ATHLA : Journal of Arabic Teaching, Linguistic And Literature, 1, (2), 2020

$$
\begin{aligned}
& \text { - اغلق عين واحدة - } \\
& \text { - يشهد تلفزيون من مسافة قريبة } \\
& \text { ج. علامات الشكوى } \\
& \text { - يشكو من الصداع و الفثيان و الدوار } \\
& \text { - غير واضح في مشاهدة } \\
& \text { - عيون الحكة } \\
& \text { - - حساسة اللضوء } \\
& \text { تحليل الأخطإ نطق المفردات المقرءة }
\end{aligned}
$$

بناء على نتائج المقابلة مع أستاذ أغوس رحمدي و التلاميذ و الملاحظة و التوثيقة، وجد على نتائج البحث عن تحليل الأخطأ نطق المفردات المقروءة للتلاميذ المكفوفين بالمدرسة العالية الإسلامية الحكومية الثانية كالتين، هذا وصف البحوث التي حُصلت الباحثة، كما يلي:

ا ـ الأخطإ النطق للتلاميذ المكفوفين

أ. أل أخطأ بالإبدال

في نطق المفردات للتلاميذ المكفوفين أخطأ غالبا ما يشعر التلاميذ المكفوفين بالحيرة في نطق حروف الهجائية مثل بين السين والشين، وبين الهمزة والعين، وبين السين والصاد،

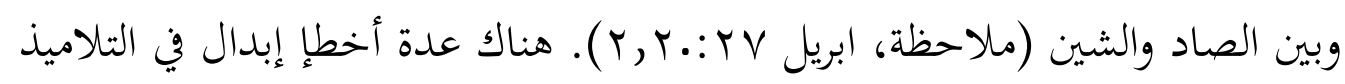
المعاقين ضعف البصر في ارتكاب أخطإ في نطق المفردات بما في ذلك مايلي:

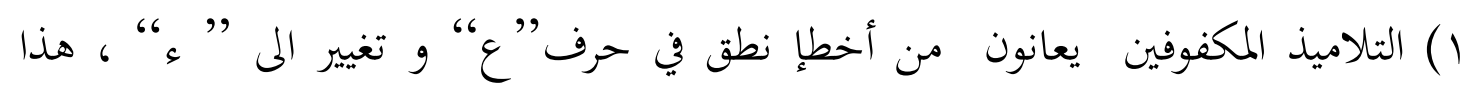

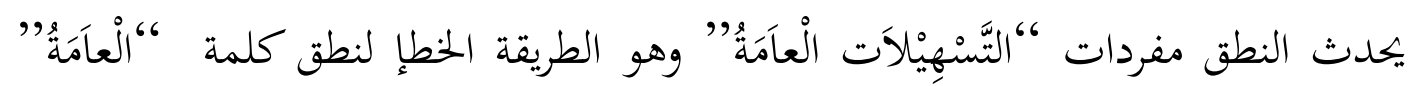

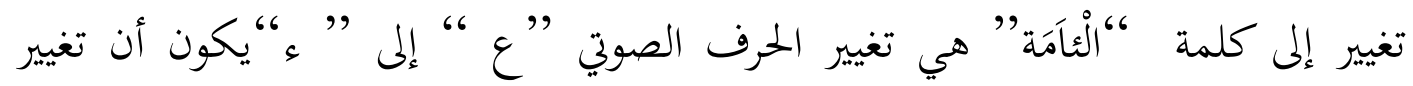
المعنى. يرى من حيث مخارج الحروف. حروف ء و ع لها إختلافات ، الحروف ء هو خخاريج الحروف من الحلق العلوي بينما تكون حروف ع مخاريج الحروف من الحلق الوسط. وقد تم النظر اليها من طبيعة الرسالة حروف ء خصائص جهر و شدة و إستفال و إنفتاح وإصمات. ينما تكون حروف ع خصائص جهر و توسط و إستفال و إنفتاح

$$
\text { وإصمات. ( محمد سبحان، ول }
$$


r) التلاميذ المكفوفين يعانون من أخطإ نطق في حرف “"ص " تغيير الى " س"، ، هذا

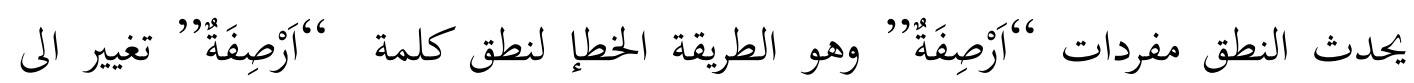

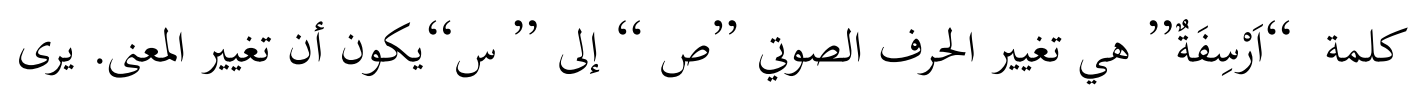
من حيث مخارج الحروف. حروف ص و س لها إختلافات ، الحروف ص هو مخاريج

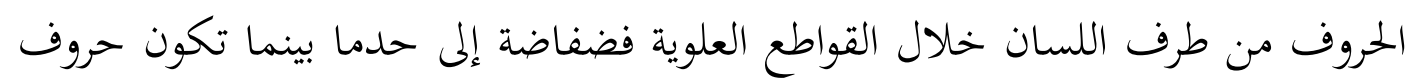

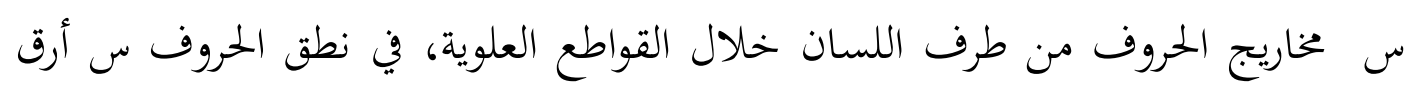

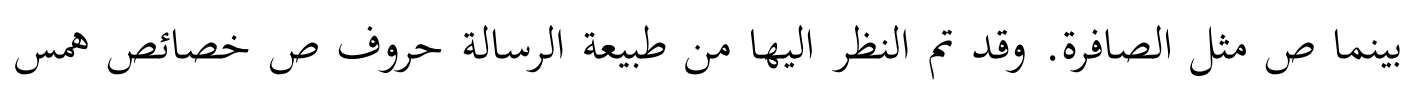

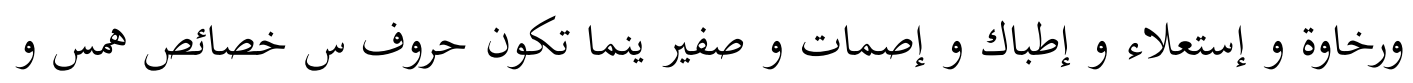

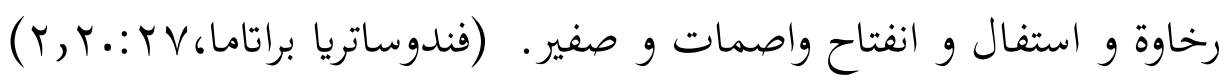

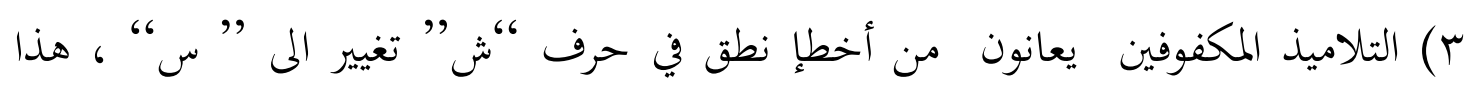

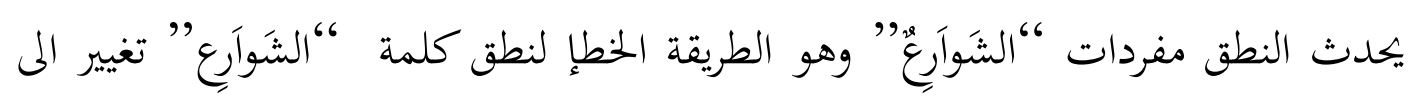

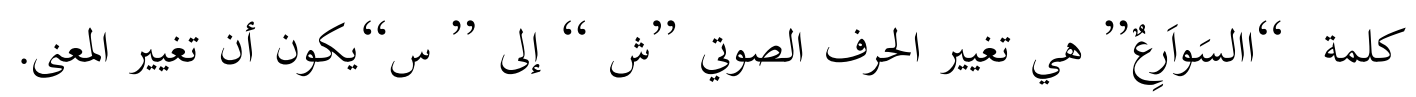

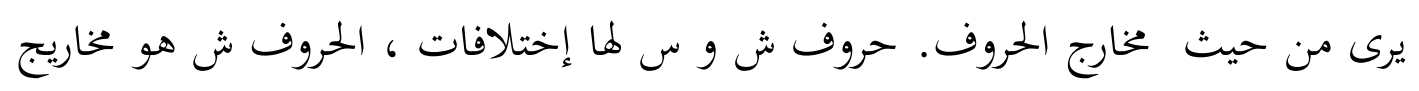
الحروف السان الوسط مواز للحنك الصلب العلوي بينما تكون حروف سروف مخرف مخريج الحروف من طرف اللسان خلال القواطع العلوية. وقد تم النظر اليها من طبيعة الرسالة حروف ش خصائص همس و رخاوة و إستفال و إنفتاح وإصمات و تغشي بينما تكون

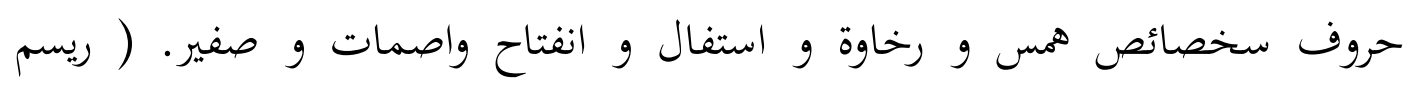
أنجرايني، (r, Y.:YV

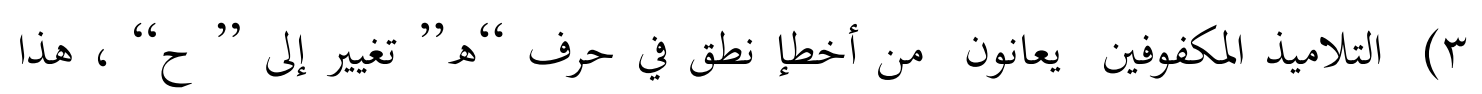

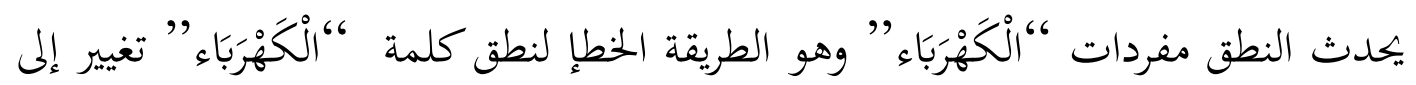

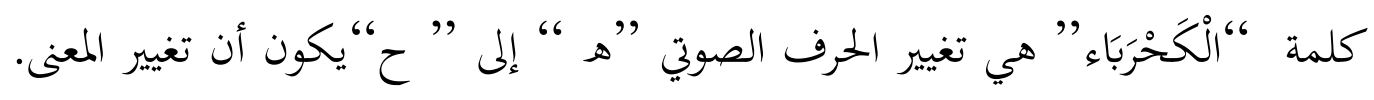

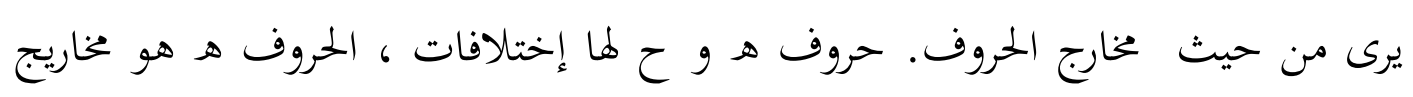

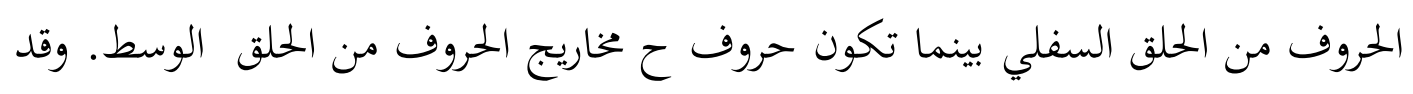
تم النظر اليها من طبيعة الرسالة حروف هـ خصائص همس و رخاوة و إستفال و إنفتاح 
وإصمات. ينما تكون حروف ح خصائص همس و رخاوة و إستفال و إنفتاح وإصمات.

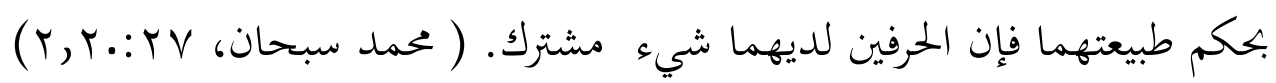

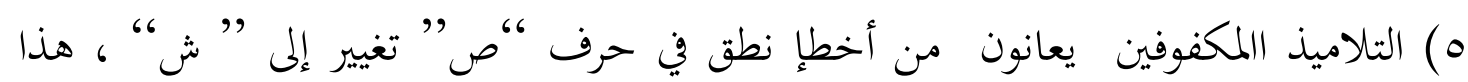

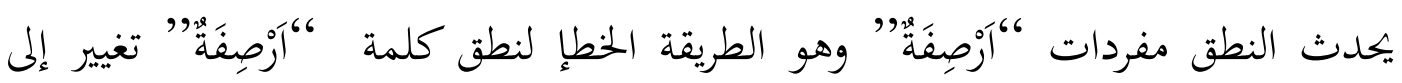

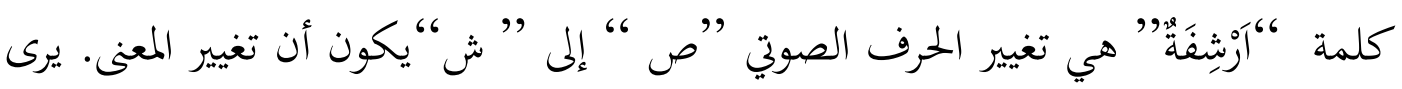

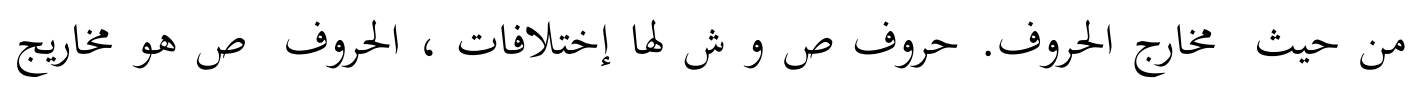

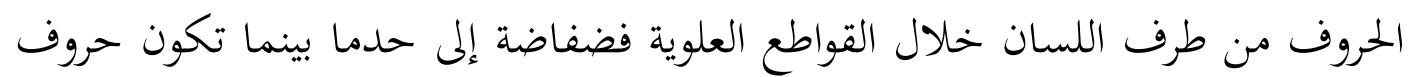
ش مخاريج الحروف من السان الوسط مواز للحنك الصلب العلوي. وقد تم النظر اليها من طبيعة الرسالة حروف ص خصائص همس ورخاوة و إستعلاء و إطباك و إصمات و و صفير ينما تكون حروف ش خصائص همس و رخاوة و إستفال و إنفتاح وإصمات

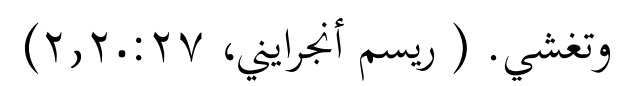

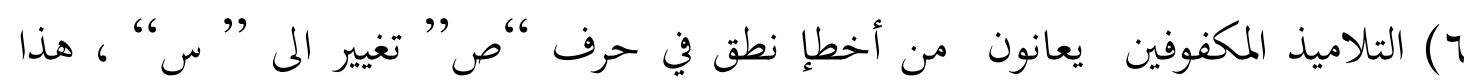

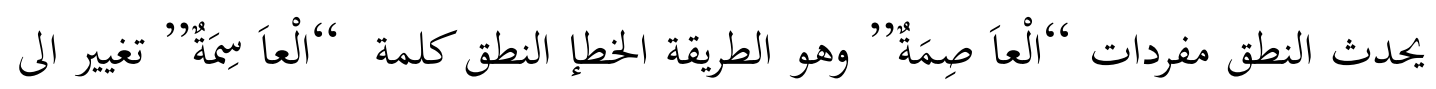

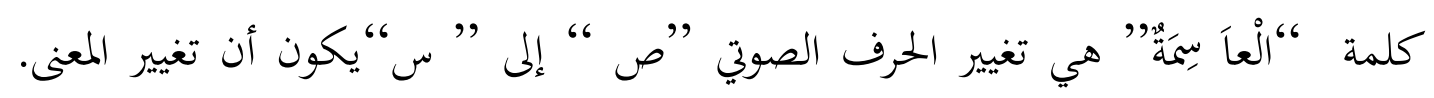
يرى من حيث مخارج الحروف. حروف ص و س لها إختلافات ، الحروف ص هو مخير لحريج

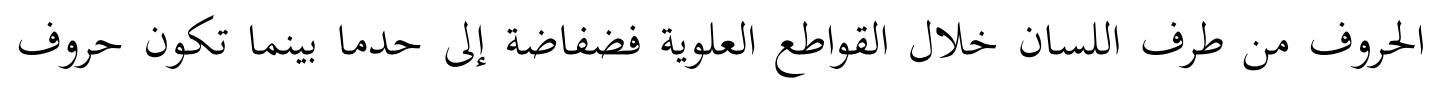
س مخاريج الحروف من طرف اللسان خلال القواطع العلوية، في نطق الحروف س أرق إقله

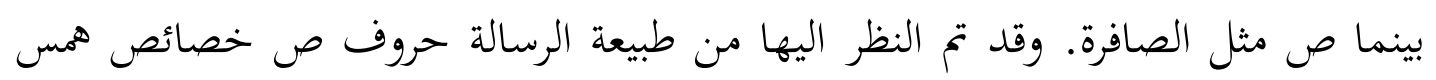

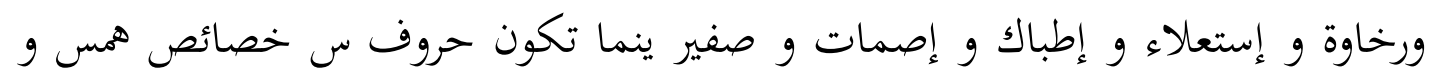

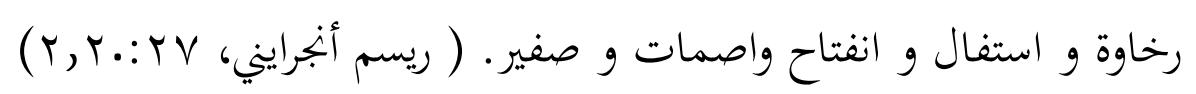

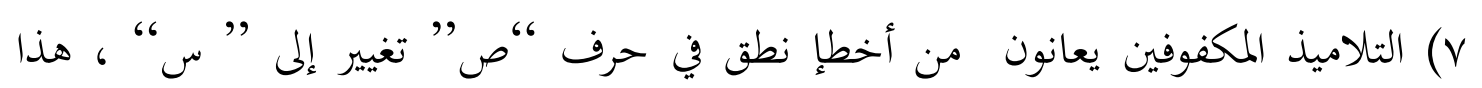

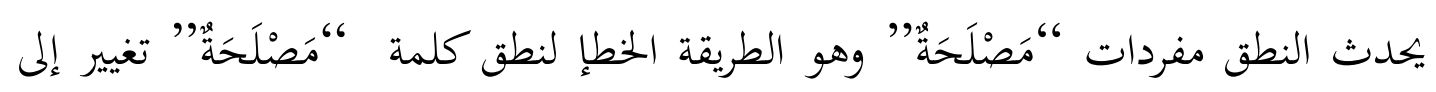

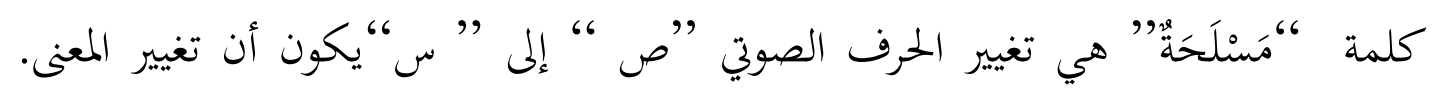
يرى من حيث مخارج الحروف. حروف ص و س لها إختلافات ، الحروف ص هو هير مخاريج

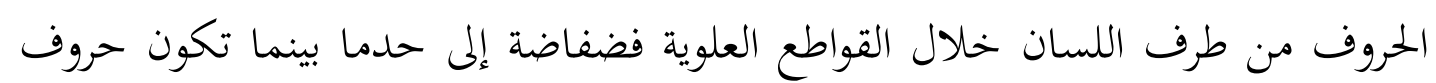


س مخاريج الحروف من طرف اللسان خلال القواطع العلوية، في نطق الحروف س أرق

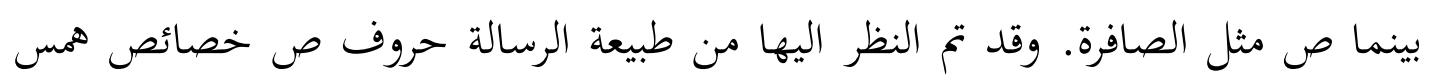

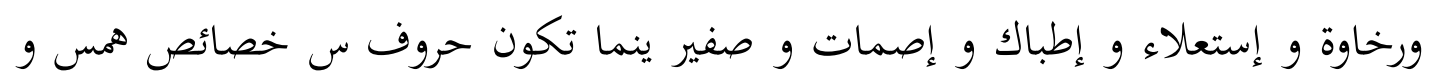

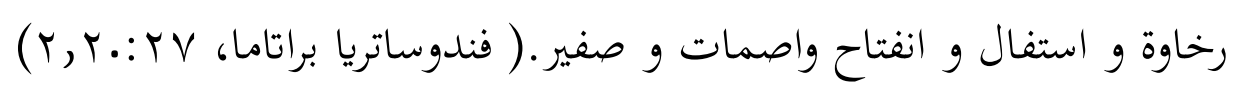

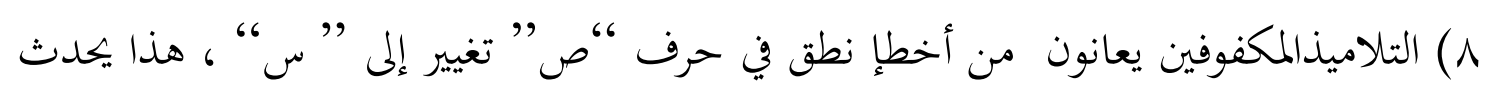

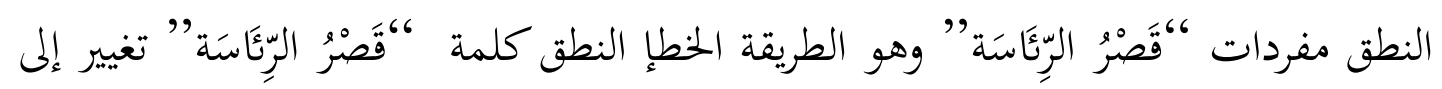

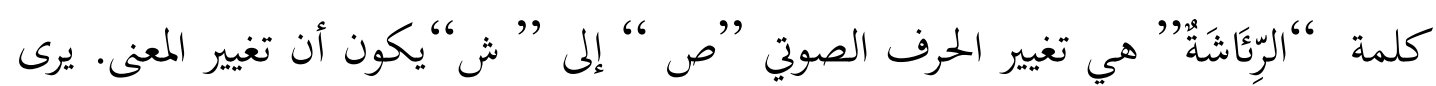

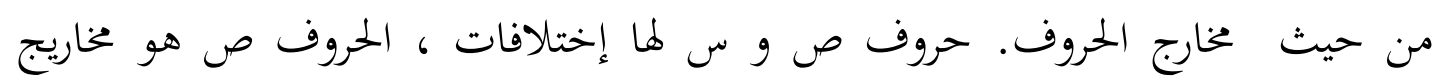

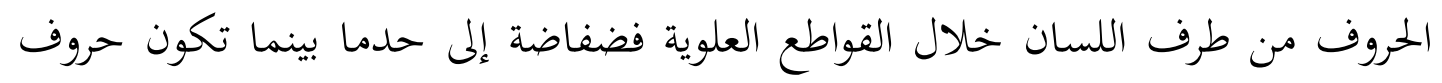

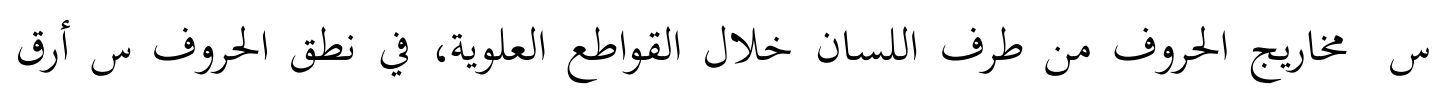

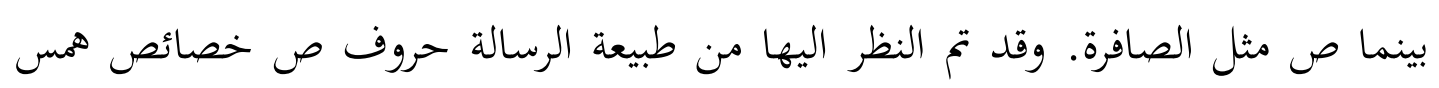

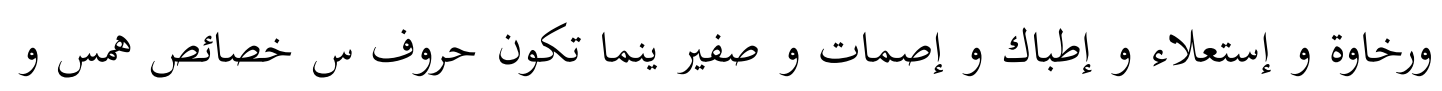

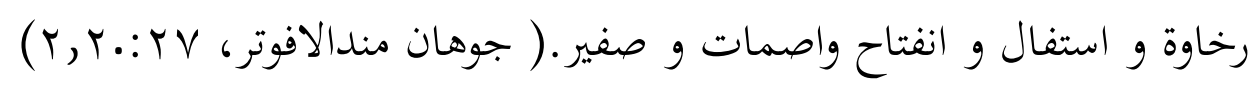

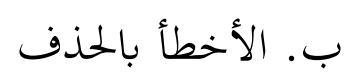

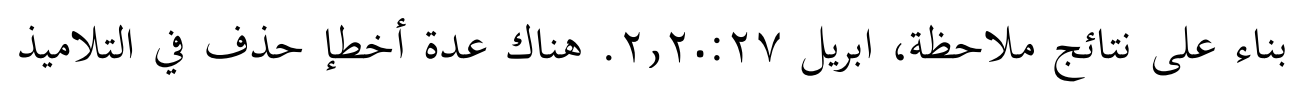
المكفوفين في ارتكاب أخطإ في نطق المفردات بما في ذلك ماءئ مايلي:

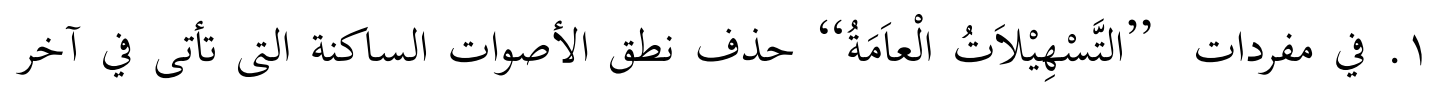

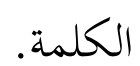

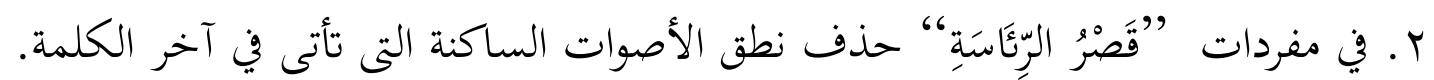

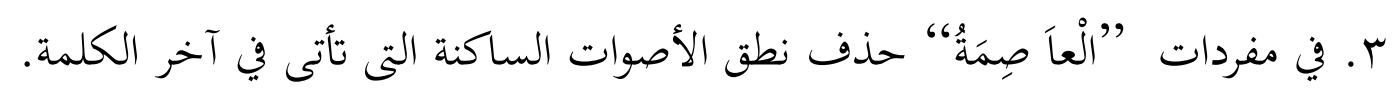
ج. الأخطأ بالإضافة

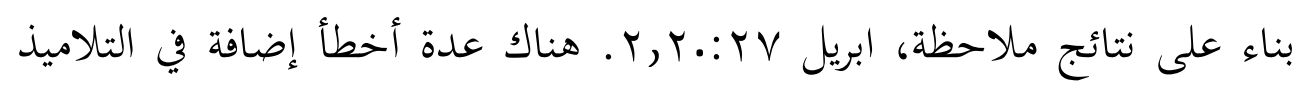

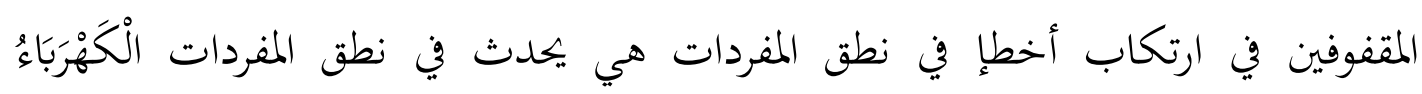

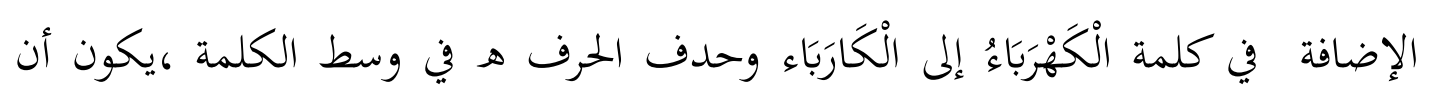

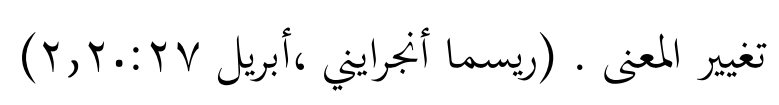


الأسباب من الأخطاٍ في النطق للتلاميذ المكفوفين

أما بالنسبة العوامل التي تؤدي الى أخطإ في نطق المفردات المقروءة وفقا لأحمد علي لئي

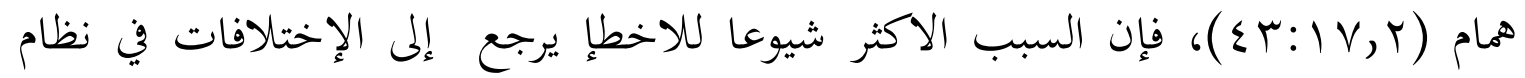

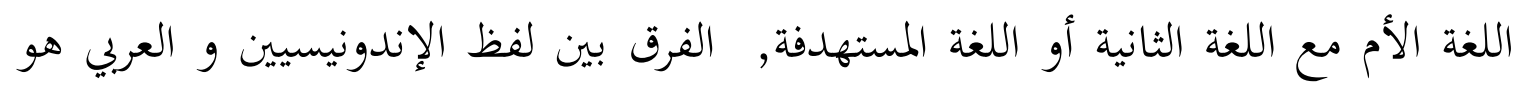
العامل الرئيسي الذي يمكن أن يؤدي إلى أخطإ نطق في التلاميذ المكفوفين . في اللغة العبية هناك رسائل غير موجودة في اللغة الإندونيسية كحرف ع و ش و ث و ذو ص ص , لذايجد التلاميذ المكفوفين في النطق هذذه الرسائل, لأن معظم التلاميذ المكفوفين لم لم تتعلموا سوى العربية الجديدة منذ المدرسة العالية.

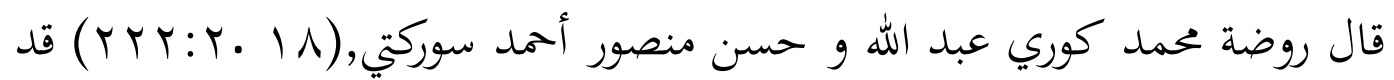

يكون المعلم سبباً لوقوع المتعلمين في الأخطإ كأن يعاني المعلم من مشكلة نطق الأصوات

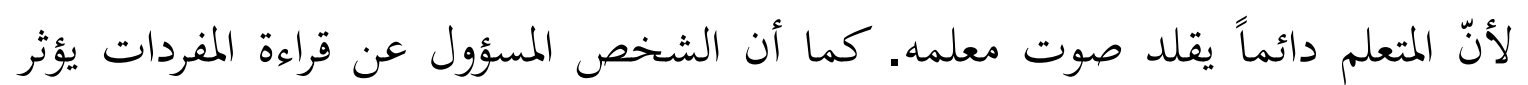

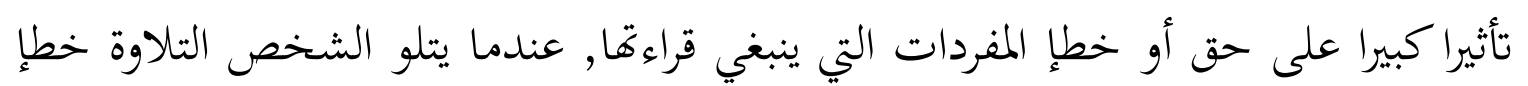

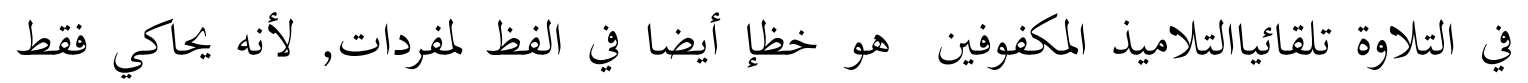
ماهو يقرأ.

في أيمن عبد الرحمن العقباوي الميكانزم السمعى الذي يقوم بالتمييز بين النطق

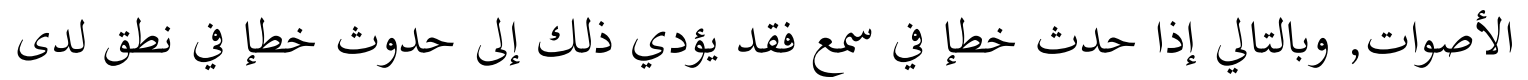
الأطفل المكفوفين لأن الأطفل لا يمكنه رؤية كتابة و فم المعلم. كما يمكن أن تؤثر أخطأ السمع على التلاميذ المكفوفين في تكليفهم المفردات, لأن عندما يكون لتلاميذ المكفوفين مخطئين في الإستماع في الإنصات المى المفردات عند نطق يكون خطإ أيضا.

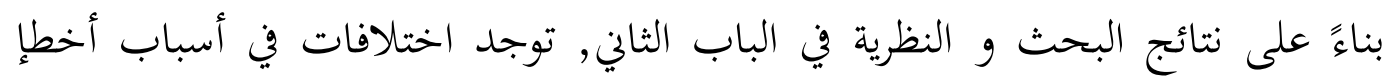
نطق في التلاميذ المكفوفين التي يسببها عدم قدرة التلاميذ على رؤية فم المعلم عند تلاوة المفردات و التلاميذ و عدم معرفة التلاميذ لمعنى قرأة المفردات و عامل وسائط مكالمة الفيديو. 

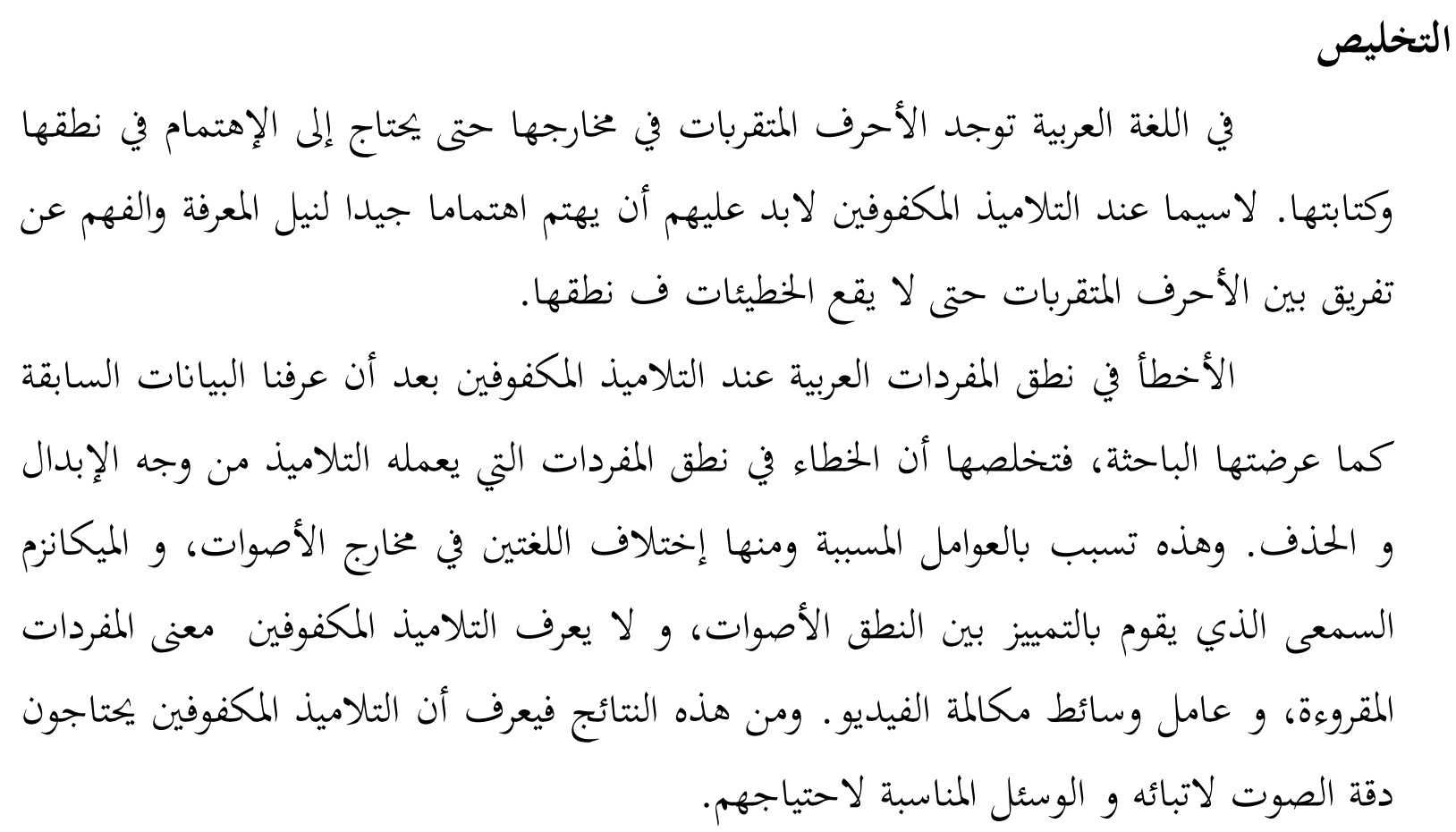

Hamid, Abdul.dkk.2008. Pembelajaran Bahasa Arab.Malang : UIN Malik Press

Hijriyah, Umi. 2018. Analisis Pembelajaran Mufrodat dan Struktur Bahasa Arab di Madrasah Ibtidaiyah. Surabaya : CV Gemilang

Moleong, J Lexy. 2017. Metodelogi Penelitian Kualitatif. Bandung : PT Remaja Rosda Karya.

Sugiyono.2017. Metode Penelitian Pendidikan. Bandung : Alfabeta

Musthafa, Izzuddin dab Acep Hermawan. 2018. Metode Penelitian Bahasa Arab. Bandung : PT Remaja Rosda Karya.

Putranto, Bambang. 2015. Tips Menangani Siswa yang Membutuhkan Perhatian Khusus. Yoyakarta : DIVA Press

Thompson, Jenny. 2010. Memahami Anak Berkebutuhan Khusus. PT Gelora Aksara Pratama

Hadi, Purwaka. 2007. Komunikasi Aktif Bagi Tunanetra. Departemen Pendidikan Nasional,Direktorat Jenderal Pendidikan Tinggi, Direktorat Ketenagaan

Muhammad, Jamila K.A. 2008. Special Education For Special Childern. Makasar : Mizan Media Utama (MMU) 
Rinarki, Jati Atmaja.2018. Pendidikan dan Bimbingan Anak Berkebutuhan Khusus. Bandung : PT Remaja Rosda Karya.

Guntur, Henry Taringan.2009. Pengajaran Sintaksis. Bandung : Angkasa.

Nuha, Ulin. 2016, Ragam Metodelogi dan Media Pembelajaran Bahasa Arab. Yoyakarta :

Diva Press

$$
\begin{aligned}
& \text { دمهوري ــ } 1 \text { • ب ـ الأخطاء اللغوية الكتابية للى طلاب قسم اللغة العببية. } \\
& \text { سوريادارما،يوكي. } 0 \text { م • ب .المقارنة بين علم اللغة التقابلي وتحليل الأخطاء. } \\
& \text { علي، أحمدهام . V V • r . تحليل الأخطاء في تعليم اللغات الأجنبية : دارالكتب العلمية. } \\
& \text { سوسن،بوغار • } 7 \text { ا • r. دراسة و تحليل أخطاء التعرف على الكلمات المكتوبة عند الطفل المصاب } \\
& \text { بعسر القراة النمائي. } \\
& \text { روضة محمد كوري عبد الله وأخوها .تحليل الأخطإ اللغوبة الشائعة للى الطلاب الأنراك (درامة } \\
& \text { وصغية تحليلية ) (2018: Nol 1.19. No } 1 \text { March) . } \\
& \text { عبدالرحمن ،أيمن العقباوي. برنامج إضطرابات النطق و الكالام في مرحلة الطفولة. }
\end{aligned}
$$

